\title{
The Profile of Type 1 Leprosy Reaction at Leprosy Division of Dermatology and Venerology Outpatient Clinic of Dr. Soetomo General Academic Hospital, Surabaya, Indonesia
}

\author{
Brigita Ika Rosdiana $^{1}$, Linda Astari ${ }^{1}$, Astindari ${ }^{1}$, Cita Rosita Sigit Prakoeswa ${ }^{1}$, Iskandar \\ Zulkarnain $^{1}$, Damayanti ${ }^{1}$ D, Budi Utomo², M. Yulianto Listiawan ${ }^{1}$ \\ ${ }^{1}$ Department of Dermatology and Venereology, Faculty of Medicine/Dr. Soetomo General Academic \\ Hospital, Surabaya, Indonesia \\ ${ }^{2}$ Department of Public Health Sciences, Faculty of Medicine, Universitas Airlangga, Surabaya, \\ Indonesia
}

\begin{abstract}
Background: Leprosy is a chronic infectious disease caused by Mycobacterium leprae. Type 1 leprosy reaction is a delayed hypersensitivity reaction caused by the increased response of cellular-mediated immunity to the Mycobacterium leprae antigen on the skin and nerves with a reversal result. The clinical manifestation includes inflammation which can cause skin and nerve lesions, swell, to permanent disabilities. Purpose: To describe the demographic and clinical profile of type 1 leprosy reaction at the Leprosy Division of the Dermatology and Venerology Outpatient Clinic of Dr. Soetomo General Academic Hospital in 2017-2019. Methods: This was a descriptive study. We used secondary data from the medical records of leprosy patients at the Leprosy Division of Dermatology and Venereology outpatient clinic, Dr. Soetomo General Academic Hospital Surabaya, from January 2017 to December 2019. Result: Out of 364 patients, 65 (17.9\%) had type 1 reactions. They were mostly in productive age at $35-55$ years old $(56.9 \%)$. The patients were predominantly male $(75.4 \%)$, with normal nutritional status (98.5\%) and negative bacterial index (72.3\%). The most common types of leprosy were BB (Borderline) with $61.6 \%$ and BL (Borderline Lepromatous) with 20.8\%. All patients took WHO (World Health Organization) MDT (Multi Drug Therapy) MB (Multi-Bacillary). Conclusion: The profile of type 1 leprosy reaction at the Leprosy Division of Dermatology and Venerology Outpatient Clinic of Dr. Soetomo General Academic Hospital in 2017-2019 shows an average data as follows: age 35-55 years, male, normal nutritional status, negative bacterial index, leprosy type BB.
\end{abstract}

Keywords: leprosy, type 1 reaction, Mycobacterium leprae, infectious disease.

Correspondence: M. Yulianto Listiawan, Department of Dermatology and Venerology Faculty of Medicine, Universitas Airlangga / Dr. Soetomo General Academic Teaching Hospital, Surabaya, Jl. Mayjen Prof. Dr. Moestopo No. 6-8 Surabaya 60131, Indonesia. Phone: 0811323730, e-mail: yuliantowawan@yahoo.com.

Article info | Submited: 22-5-2021, Accepted: 14-7-2021, Published: 30-11-2021

\section{BACKGROUND}

Leprosy is a chronic infectious disease caused by Mycobacterium leprae, and it mainly affect the skin and nerves. It is highly contagious, but its morbidity is low because a large portion of the population is naturally resistant to this disease. The diagnosis is established based on skin and neurologic examination. ${ }^{1}$

Indonesia has the third-highest cases number of leprosy infection globally, after India and Brazil. ${ }^{2}$ In 2017, the Indonesian Ministry of Health reported that the incidence of leprosy in Indonesia is 6.08 new cases per 100,000 population. Twelve provinces have new cases detection rate above 10 cases per 100,000 population, and East Java has the highest number of leprosy patients. ${ }^{3}$

Type 1 leprosy reaction is an immunological phenomenon that occurs before, during, or after the completion of multi-drug therapy (MDT). It's a delayed hypersensitivity reaction caused by an increase in cellular immunity response to Mycobacterium leprae antigen on the skin and nerves of leprosy patients. ${ }^{4}$ Clinical manifestations of type 1 reactions are inflammation of the skin and nerves that can cause skin and nerve lesions, edema, and permanent disability. 5,6

Leprosy reaction is one of the causes of morbidity in leprosy patients. These immune-mediated complications can cause rapid nerve damage, resulting in anesthesia and weakness. They then contributed to an increased risk of injury and deformity. ${ }^{7}$ The incidence of type 1 reactions varies around $19.7 \%-30$ $\%$ in various countries. ${ }^{6,8,9}$

\section{METHODS}

This descriptive study aimed to describe the demographic and clinical profile of type 1 leprosy reactions in leprosy patients, particularly patients 
treated at the Leprosy Division of Dermatology and Venerology Outpatient Clinic of Dr. Soetomo General Academic Hospital in 2017-2019. We used secondary data obtained from medical records.

The inclusions criterion was patients diagnosed with type 1 leprosy reaction, as described in their medical records, at the Leprosy Division of the Dermatology and Venerology Outpatient Clinic of Dr. Soetomo General Academic Hospital from January 2017 to December 2019.

\section{RESULT}

There were 364 leprosy cases managed at Dr. Soetomo General Academic Hospital between January
2017 and December 2019. Table 1 shows the demographic distribution of the patients. Of the 364 cases, $17.9 \%$ of them had type 1 leprosy reaction diagnosed. We further profiled their age, sex, nutritional status, bacterial index, types of leprosy, and therapeutic regimen. Most patients were mostly in productive age at $35-55$ years old $(56,9 \%)$. They were predominantly males $(75.4 \%)$, had normal nutritional status (98.5\%), and had negative bacterial index (72.3\%). The most common types of leprosy were BB (Borderline) with $61.6 \%$, and BL (Borderline Lepromatous) with $20.8 \%$. All patients took WHO (World Health Organization) MDT-MB (Multibacillary).

Table 1. Type 1 leprosy reaction patient distribution in Dr. Soetomo General Academic Hospital in January 2017December 2019

\begin{tabular}{|c|c|c|c|c|}
\hline \multirow{2}{*}{ Characteristics } & \multicolumn{3}{|c|}{ Year } & \multirow{2}{*}{ Total $(\%)$} \\
\hline & $2017(\%)$ & $2018(\%)$ & $2019(\%)$ & \\
\hline \multicolumn{5}{|l|}{ Patient } \\
\hline Leprosy division & $135(37.1)$ & $125(34.3)$ & $104(28.6)$ & $364(100)$ \\
\hline Leprosy without a reaction & $70(19.2)$ & $70(19.2)$ & $50(13.7)$ & $190(52.2)$ \\
\hline Leprosy with type 1 reaction & $26(7.14)$ & $18(4.9)$ & $21(5.8)$ & $65(17.9)$ \\
\hline \multicolumn{5}{|l|}{ Age (year) } \\
\hline$<15$ & $0(0)$ & $1(1.5)$ & $0(0)$ & $1(1.5)$ \\
\hline $15-34$ & $8(12.3)$ & $4(6.2)$ & $7(10.8)$ & $19(29.2)$ \\
\hline $35-55$ & $15(23.1)$ & $10(15.4)$ & $12(18.5)$ & $37(56.9)$ \\
\hline$>55$ & $3(4.6)$ & $3(4.6)$ & $2(3.1)$ & $8(12.3)$ \\
\hline \multicolumn{5}{|l|}{ Sex } \\
\hline Male & $21(32.2)$ & $12(18.5)$ & $16(24.6)$ & $49(75.4)$ \\
\hline Female & $5(7.7)$ & $6(9.2)$ & $5(7.7)$ & $16(24.6)$ \\
\hline \multicolumn{5}{|l|}{ Nutritional Status } \\
\hline Under & $1(1.5)$ & $0(0)$ & $0(0)$ & $1(1.5)$ \\
\hline Normal & $25(38.5)$ & $18(27.7)$ & $21(32.3)$ & $64(98.5)$ \\
\hline Over & $0(0 \%)$ & $0(0 \%)$ & $0(0 \%)$ & $0(0 \%)$ \\
\hline \multicolumn{5}{|l|}{ Bacterial Index } \\
\hline Negative & $19(29.2)$ & $12(18.5)$ & $16(24.6)$ & $47(72.3)$ \\
\hline $1+$ & $3(4.6)$ & $1(1.5)$ & $4(6.2)$ & $8(12.3)$ \\
\hline $2+$ & $4(6.2)$ & $4(6.2)$ & $1(1.5)$ & $9(13.8)$ \\
\hline $3+$ & $0(0)$ & $1(1.5)$ & $0(0)$ & $1(1.5)$ \\
\hline $4+$ & $0(0)$ & $0(0)$ & $0(0)$ & $0(0)$ \\
\hline$>4+$ & $0(0)$ & $0(0)$ & $0(0)$ & $0(0)$ \\
\hline \multicolumn{5}{|l|}{ Types of Leprosy } \\
\hline TT & $0(0)$ & $0(0)$ & $0(0)$ & $0(0)$ \\
\hline BT & $0(0)$ & $0(0)$ & $0(0)$ & $0(0)$ \\
\hline BB & $12(18.5)$ & $13(20.0)$ & $15(23.1)$ & $40(61.6)$ \\
\hline BL & $12(18.5)$ & $4(6.2)$ & $4(6.2)$ & $20(20.8)$ \\
\hline LL & $2(3.1)$ & $1(1.5)$ & $2(3.1)$ & $5(7.7)$ \\
\hline Neural & $0(0)$ & $0(0)$ & $0(0)$ & $0(0)$ \\
\hline \multicolumn{5}{|l|}{ Therapeutic Regimen } \\
\hline PB (Pauci-bacillary) & $0(0)$ & $0(0)$ & $0(0)$ & $0(0)$ \\
\hline MB (Multi-bacillary) & $26(40.0)$ & $18(27.7)$ & $21(32.3)$ & $65(100)$ \\
\hline
\end{tabular}

$\mathrm{TT}=$ polar tuberculoid; $\mathrm{BT}=$ borderline tuberculoid; $\mathrm{BB}=$ borderline borderline; $\mathrm{BL}=$ borderline lepromatous; $\mathrm{LL}=$ polar lepromatous 


\section{DISCUSSION}

This retrospective study shows 364 cases of leprosy managed at the Dr. Soetomo General Academic Hospital from January 2017 to December 2019. Of those cases, $17.9 \%$ ( 65 cases) recorded type 1 leprosy reactions. The age distribution was $35-55$ years old $(56.9 \%)$, a productive age. This is similar to previous studies, which report that most type 1 leprosy reaction patients were $30-60$ years old. ${ }^{10-12}$ Age is an independent risk factor for the incidence of type 1 leprosy reactions. Patients over 20 years of age are more likely to experience type 1 leprosy reactions. There are reasons why type 1 leprosy reactions are common in adult patients. Type 1 leprosy reaction is mainly caused by a high Th1 level, a more common immune response in adults. Also, adults have more memory $\mathrm{T}$ cells, causing a secondary antigen crossreaction from Mycobacterium infection other than $M$. leprae, for example, Mycobacterium tuberculosis. This cross-reaction then resulted in type 1 leprosy reactions. ${ }^{8,12}$ Age is an important risk factor in determining the incidence and severity of type 1 leprosy reactions. ${ }^{12}$

The patients were predominantly males (75.4\%), which is in accordance with other studies. ${ }^{8,13,14}$ There are two reasons why most leprosy patients were males. First, leprosy itself is a very stigmatized disease so people tend to postpone seeking healthcare, but it is found that women in particular tend to do it later than male. ${ }^{15}$ Secondly, it is said that leprosy reaction is mostly related to stress. Therefore, it is more common in male patients. Stress is associated with immune responses and non-specific responses to lymphocyte proliferation, the emergence of $\mathrm{T}$ cells, specific antigens, activation of macrophages, changes in the balance of Th1 and Th2, and the release of cytokines such as IL-6s. ${ }^{9,16}$ Those immune responses can trigger type 1 leprosy reaction. ${ }^{1}$

Most patients $(98.5 \%)$ had normal nutritional status. This is not in line with a previous study that reports that patients with type 1 leprosy reaction are more likely to be undernutrition. ${ }^{17}$ It is reported that leprosy patients suffer from severe oxidative stress due to malnutrition and poor immunity. Lack of nutrients can lead to destruction of the body's defenses and immune suppression. Some micronutrients are important to maintaining the body's defenses and immune function, such as immune response and antibody production. ${ }^{17,18}$ This discrepancy is influenced by a lack of research related to data collection on nutritional status in the outpatient clinic of Dr. Soetomo General Academic Hospital, Surabaya. The nutritional status data were obtained from measurements of patient's height and weight.
However, some medical records did not specify patient's height and weight.

Most patients had a negative bacterial index $(72.3 \%)$. This is not in line with previous studies, which reported a higher incidence of the negative bacterial index in patients with type 1 leprosy reactions. ${ }^{19-22}$ This discrepancy can be caused by the low number of data used in this study. For example, a study by Antunes in 2013 involved 440 patients, where 211 of them had type 1 leprosy reaction. Also, another study by Hungria in 2016 involved 753 leprosy patients, and 418 of them had type 1 leprosy reaction diagnosed.

The most common types of leprosy were BB $(61.6 \%)$ and BL $(20.8 \%)$. These are similar to previous studies. Antunes and colleagues in 2013 reported that $68.5 \%$ of patients with type 1 leprosy reactions had the borderline type of leprosy. ${ }^{20}$ A study conducted by Hungria and colleagues in 2016 also reported a similar result. They found that $98.5 \%$ of patients had the borderline type of leprosy. ${ }^{19}$ Borderline is the most common type of leprosy that causes type 1 leprosy reaction. This is because borderline type has a very unstable immunity that it can easily stimulate a cellmediated hypersensitivity caused by increased bacteria level. ${ }^{14,20,23}$

All of the patients (100\%) took WHO MDT-MB. This is similar to previous conducted studies. Hungria and colleagues in 2016 reported that MB patients had a higher tendency to develop leprosy reactions. Other studies also showed that leprosy reactions mainly occur in patients receiving MDT-MB. ${ }^{20,24}$ The type 1 leprosy reaction is related to the success of therapy in the MDT-MB because the antigen from bacterial degradation will stimulate the body to produce antibodies and generate a cell-mediated immune response (CMI). ${ }^{25,26}$ The CMI then causes an inflammatory reaction to the skin and nerves, resulting in a type 1 leprosy reaction. ${ }^{25}$

The limitation of this study is that we used secondary data obtained from the medical records, which in some cases, are not complete. It should be noted that a complete medical record is important for early detection and evaluation of the disability. Every clinician should be aware of the importance of a complete medical record. For future studies, we recommend a study with a bigger sample size.

In conclusion, there was a total of 65 patients (17.9\%) diagnosed with type 1 leprosy reactions. The age distribution was $35-55$ years old $(56.9 \%)$, a productive age. The patients were predominantly males $(75.4 \%)$, and they had normal nutritional status (98.5\%) negative bacterial index (72.3\%). The most 

General Academic Hospital, Surabaya, Indonesia

common types of leprosy were BB (61.6\%) and BL (20.8\%). All patients took MDT-MB.

\section{REFERENCES}

1. Lastória JC, Abreu MAMM de. Leprosy: review of the epidemiological, clinical, and etiopathogenic aspects - part 1. An Bras Dermatol. 2014;89(2):205-18.

2. Peters RMH, Dadun, Lusli M, Miranda-Galarza B, van Brakel WH, Zweekhorst MBM, et al. The Meaning of Leprosy and Everyday Experiences: An Exploration in Cirebon, Indonesia. J.Trop.Med. 2013;2013:1-10.

3. Santé World Health Organization = Organisation mondiale de la Santé. Global leprosy update, 2018: moving towards a leprosy-free world Situation de la lèpre dans le monde, 2018: parvenir à un monde exempt de lèpre. Weekly Epidemiological Record = Relevé épidémiologique hebdomadaire. 2019; 94(35/36): 389-411.

4. Kar HK, Kumar B. IAL textbook of leprosy [Internet]. New Delhi: Jaypee Brothers Medical Publishers; 2010 [cited 2021 Mar 10]. Available from:

https://library.dctabudhabi.ae/sirsi/detail/342772

5. Nery JA da C, Bernardes Filho F, Quintanilha J, Machado AM, Oliveira S de SC, Sales AM. Understanding the type 1 reactional state for early diagnosis and treatment: a way to avoid disability in leprosy. An Bras Dermatol. 2013 Oct;88(5):787-92.

6. Suchonwanit P, Triamchaisri S, Wittayakornrerk S, Rattanakaemakorn P. Lepra reaction in Thai Population: A 20-Year Retrospective Study. Dermatol Res Pract. 2015;2015:1-5.

7. Raffe SF, Thapa M, Khadge S, Tamang K, Hagge D, Lockwood DNJ. Diagnosis and treatment of lepra reactions in integrated services--the patients' perspective in Nepal. PLoS Negl Trop Dis. 2013;7(3):e2089.

8. Aisyah I, Agusni I. A Retrospective Study: Profile of New Leprosy Patients. Periodical of Dermatology and Venereology. 2018;30:40-7.

9. Martelli CMT, Maroja M de F, Pardillo F, Stefani MMA, Villahermosa L, Scollard DM, et al. Risk Factors for Lepra reactions in Three Endemic Countries. AJTMH. 2015;92(1):108-14.

10. Motta A, Pereira K, Tarquinio D, Vieira M, Miyake K, Foss N. Lepra reactions: coinfections as a possible risk factor. Clinics. 2012;67(10):1145-8.

11. Cellona RV, Balagon MaVF, Gelber RH, Abalos RM. Reactions Following Completion of 1 and 2
Year Multidrug Therapy (MDT). AJTMH 2010;83(3):637-44.

12. Ranque B, Nguyen VT, Vu HT, Nguyen TH, Nguyen NB, Pham XK, et al. Age Is an Important Risk Factor for Onset and Sequelae of Reversal Reactions in Vietnamese Patients with Leprosy. Clin Infect Dis. 2007;44(1):33-40.

13. Thomas EA, Williams A, Jha N, Samuel CJ. A Study on Lepra Reactions from a Tertiary Care Center in North India. IJMRP. 2017;3(3):162-6.

14. Antunes DE, Ferreira GP, Nicchio MVC, Araujo S, Cunha ACR da, Gomes RR, et al. Number of lepra reactions during treatment: clinical correlations and laboratory diagnosis. Rev Soc Bras Med Trop. 2016;49(6):741-5.

15. Sarkar R, Pradhan S. Leprosy and women.IJWD. 2016;2(4):117-21.

16. Morey JN, Boggero IA, Scott AB, Segerstrom SC. Current directions in stress and human immune function. Curr Opin Psychol. 2015;5:13-7.

17. Rao PSS, John AS. Nutritional status of leprosy patients in India. Indian J Lepr. 2012;84(1):17-22.

18. Ribeiro de Jesus A. Micronutrientes que influyen en la resouesta inmune en la lepra. Nutricion Hospitalaria. 2014;(1):26-36.

19. Hungria EM, Oliveira RM, Penna GO, Aderaldo LC, Pontes MA de A, Cruz R, et al. Can baseline ML Flow test results predict lepra reactions? An investigation in a cohort of patients enrolled in the uniform multi-drug therapy clinical trial for leprosy patients in Brazil. Infect Dis Poverty. 2016;5(1):110.

20. Antunes DE, Araujo S, Ferreira GP, Cunha ACSR da, Costa AV da, Gonçalves MA, et al. Identification of clinical, epidemiological and laboratory risk factors for lepra reactions during and after multi-drug therapy. Mem Inst Oswaldo Cruz. 2013;108(7):901-8.

21. Brito M de F de M, Ximenes RAA, Gallo MEN, Bührer-Sékula S. Association between lepra reactions after treatment and bacterial load evaluated using anti PGL-I serology and bacilloscopy. Rev Soc Bras Med Trop. 2008;41 Suppl 2:67-72.

22. Sousa ALOM, Stefani MMA, Pereira GAS, Costa MB, Rebello PF, Gomes MK, et al. Mycobacterium leprae DNA associated with type 1 reactions in single lesion paucibacillary leprosy treated with single dose rifampin, ofloxacin, and minocycline. Am J Trop Med Hyg. 2007;77(5):829-33.

23. Fava VM, Manry J, Cobat A, Orlova M, Van Thuc $\mathrm{N}, \mathrm{Ba} \mathrm{NN}$, et al. A Missense LRRK2 Variant Is a Risk Factor for Excessive Inflammatory 
Responses in Leprosy. Johnson C, editor. PLoS Negl Trop Dis. 2016 ;10(2):e0004412.

24. Fischer M. Leprosy - an overview of clinical features, diagnosis, and treatment: CME article. JDDG. 2017;15(8):801-27.

25. Spencer JS, Duthie MS, Geluk A, Balagon MF, Kim HJ, Wheat $\mathrm{WH}$, et al. Identification of serological biomarkers of infection, disease progression and treatment efficacy for leprosy. Mem Inst Oswaldo Cruz. 2012;107(suppl 1):7989.

26. Oertelt-Prigione S. Immunology and the menstrual cycle. Autoimmun Rev. 2012;11(67):A486-492. 